\title{
GOTICISMO ONTEM E HOJE: O HORROR NA REPRESENTAÇÃO DO GATO EM POE E KING
}

\author{
GOTICISM YESTERDAY AND TODAY: \\ HORROR IN CAT REPRESENTATION IN POE AND KING
}

\section{GOTICISMO AYER Y HOY: HORROR EN LA REPRESENTACIÓN DEL GATO EN POE Y REY}

\author{
Sarah Augusta Iransos Teixeira \\ Graduação em Letras - Faculdades Integradas de Jaú \\ Email: sarahteixeira08@gmail.com \\ Sarah Caroline Mazzo \\ Graduação em Letras - Faculdades Integradas de Jaú \\ Email: sarahmazzo86@gmail.com \\ Elaine Regina Cassoli \\ Doutoranda em Linguística - Universidade Federal de São Carlos - UFSCar \\ Mestre em Linguística - UFSCar \\ Docente das Faculdades Integradas de Jaú \\ Docente da FATEC - Jaú \\ E-mail: e.cassoli@gmail.com
}

\begin{abstract}
RESUMO
A Literatura de Prosa Gótica ganha forças durante a Idade Média, sustentada pelo medo do desconhecido e o imaginário popular que transcende gerações e transforma o gótico clássico no moderno terror, por volta dos séculos XVIII e XIX. O medo está presente em cada indivíduo, não somente como um sentimento, mas também como um instinto. Ainda que ele possa se manifestar de formas variadas, foram atribuídas a alguns animais, como por exemplo, aos gatos, certas crenças ligadas ao sobrenatural. Este trabalho tem como foco a transmissão do medo através da literatura e do símbolo felino e é no terreno do mistério que escolhemos dois escritores: um dos precursores do gótico e inovador do gênero, Edgar Allan Poe, e seu sucessor e referência atual para o gênero terror, Stephen King. Para sustentarmos o foco a ser discutido, analisaremos um conto de cada autor: "O gato preto" de Poe e "O gato dos infernos" de King. Partindo da ideia de que ambos os contos conservam características semelhantes, este trabalho apresenta um paralelo entre os dois textos, explorando suas diferenças, levando em consideração o contexto, o simbolismo, a estilística e inspirações de cada autor. Verificamos que Poe exerceu grande influência em seu sucessor King e que há entre os textos uma ligação que ultrapassa a coincidência, expondo também sua intertextualidade de modo minucioso. Pudemos, inclusive, observar também como as definições de medo de cada época foram exploradas em ambos os textos através da figura do gato.
\end{abstract}

Palavras-Chave: Gótico. Terror. Conto. 


\begin{abstract}
The Gothic Literature empowers itself during the Middle Ages, sustained by the fear of the unknown and by the popular imagination that transcends generations, transforming the classic gothic into the modern horror, around the ages of XVIII and XIX. Fear is part of each individual, not only like a feeling, but also like an instinct. Although fear can manifest itself in varied forms, certain beliefs linked to the supernatural have been attributed to some animals, for example, the cats. The focus of this essay is on the transmission of fear through literature and the feline symbol and it is in the field of mystery that we chose two writers: one of the forerunners of the gothic and innovator of the genre, Edgar Allan Poe, and his successor and current reference for the horror genre, Stephen King. To sustain the focus that will be discussed, we will analyze a tale of each author: Poe's "The Black Cat" and King's "The Cat From Hell." Based on the idea that both stories retain similar characteristics, this work presents a parallel between the two texts, exploring their differences, taking into account the context, symbolism, stylisticsand inspirations of each author. We verified that Poe exerted a great influence on his successor King, and that there is a connection between the texts that goes beyond coincidence, also exposing an intertextuality in detail. We were even able to observe also how the definitions of fear of each era were explored in both texts through the form of the cat.
\end{abstract}

Keywords: Gothic. Horror. Tale.

\title{
RESUMEN
}

La literatura en prosa gótica se fortalece durante laEdad Media, apuntalada por elmiedo a lasimágenesdesconocidas y populares que trasciendengeneraciones y transforma el gótico clásicoen terror moderno alrededor de lossiglos XVIII y XIX. El miedo está presente en cada individuo, no solo como unsentimiento, sino también como un instinto. Aunquepuedemanifestarse de variasmaneras, algunosanimales, como los gatos, se hanatribuido a ciertascreenciassobrenaturales. Este trabajo se enfoca enlatransmisióndelmiedo a través de la literatura y el símbolo felino y es enel terreno misterioso que elegimos dos escritores: uno de los precursores del gótico e innovador de género Edgar Allan Poe y susucesor y referenciaactual al género. Terror, Stephen King. Para apoyarel enfoque que se discute, analizaremos una historia de cada autor: "El gato negro" de Poe y "El gato delinfierno" de King. Basadoenlaidea de que ambas historiasconservan características similares, este documento presenta un paralelo entre los dos textos, explorando sus diferencias, teniendoencuentael contexto, el simbolismo, la estilística, las influencias y lasinspiraciones de cada autor. Descubrimos que Poe hatenido una gran influencia ensusucesor, King, y que existe un vínculo entre los textos que va más allá de lacoincidencia, exponiendotambiénsuintertextualidad de maneradetallada. Incluso pudimos observar cómo se exploraronlasdefiniciones de miedo de cada época en ambos textos a través de la figura del gato.

Palabras clave: Gótico. Horror. Cuento.

\section{INTRODUÇÃO}

Por que o horror atrai?

Podemos responder essa pergunta citando o Dr. Jeffrey Goldstein, um professor de psicologia social e organizacional da Universidade de Utrecht, em uma entrevista dada para a IGN (Imagine Games Network) em 2013, contextualizando-a no campo da literatura: 
As pessoas assistem filmes de terror porque elas querem ser assustadas, senão não fariam isso mais de uma vez. Você escolhe seu entretenimento, pois quer que isso afete você. Essa é a verdade sobre pessoas que buscam produtos de entretenimento como filmes de terror, que têm grande efeito. Elas querem esses efeitos. Os filmes de terror devem providenciar uma resolução justa no fim. Os caras maus pagam por isso. Ainda que as pessoas escolham assistir essas coisas, as imagens ainda são perturbadoras para muita gente. Porém, as pessoas têm a habilidade de prestar muita ou pouca atenção em algo a fim de controlarem o quanto isso as afeta, seja emocionalmente ou de qualquer outra forma (GOLDSTEIN. 2013, entrevista para IGN).

Isto é, as pessoas buscam estórias de terror - não apenas em filmes - porque querem ser levadas a certos limites psicológicos, suscitando emoções mais fortes - como o medo - de modo que essas emoções sejam exploradas, atingindo assim o objetivo do autor das estórias de terror: assustar ou chocar o leitor/espectador, levando-o a liberar adrenalina.

De acordo com o Dr. Glenn Walters, em uma entrevista para o Journal of Media Psychology (2004), os três fatores primários que fazem as estórias de terror serem atraentes são relevância, tensão e fantasia. Isto é, são três pontos que se conectam, sendo que a relevância se dá a partir da tensão criada que, por sua vez, é produto da fantasia aplicada à obra, ou seja, a estrutura da estória (atmosfera, cenário, intensidade das personagens etc.). Estes três ingredientes são cruciais para que a receita de uma boa estória de horror - que assuste e cative o leitor - atinja seu objetivo.

Desta forma, podemos inferir que o horror atrai porque os medos que partem do cotidiano, do real, atingem o imaginário ou o subconsciente, levando as pessoas a assistirem filmes ou lerem livros de terror, pois as sensações provocadas no leitor/telespectador estão, em sua totalidade, fortemente relacionadas ao pathos - a empatia do leitor para com os personagens - e à necessidade de se relacionar com o contexto apresentado na obra. Desta forma, esta pesquisa situa-se nos campos do mistério e do medo do desconhecido, levando em consideração a literatura fantástica curta, o conto e, utilizando-se de dois autores que podemos chamar de "chaves- mestras" do gênero: Edgar Allan Poe e Stephen Edwin King. As obras de ambos apresentam o símbolo do gato tanto relacionado à cultura do século XIX quanto à cultura atual, partindo de situações aparentemente comuns e fazendo emergir, a partir daí, o sobrenatural.

Diante da análise dos contos O gato preto (1843) e O gato dos infernos (1977) levantamos a seguinte questão: quais são as semelhanças e diferenças entre "O pai dos contos de terror" na literatura norte-americana e "O mestre do horror moderno"? 
O objetivo deste trabalho é evidenciar a relação existente entre ambos os textos, levando em consideração o contexto em que foram produzidos e como foram desenvolvidos até a sua fase final, de modo que possamos estabelecer uma conexão não só entre os autores, mas também entre os contos analisados, através da origem do próprio goticismo e da influência do medo nas duas produções.

Frente a essa investigação, a proposta da pesquisa visa apresentar conceitos, definições e ferramentas necessárias para estabelecer a ligação entre os autores por meio de seus contos pertencentes, dado as características, ao gênero horror.

\section{DESENVOLVIMENTO}

\subsection{Raízes da literatura gótica: $O$ conto como ferramenta do horror}

O conto é um dos gêneros da prosa de ficção, de pequena extensão, com apenas um clímax e apresenta uma história fictícia. Mas, para compreendermos melhor sua importância, devemos buscar as raízes deste gênero que, segundo os historiadores, estão nas narrativas folclóricas orais (contos populares), nos mitos e lendas, vindos de todas as partes do globo.

Apesar da abundância de crenças e histórias preservadas até o período colonial, tanto por pessoas letradas como por pessoas incultas, não havia um termo próprio para definir a prosa curta. Explica Battella (2001) que a palavra:

Novel, usada do século XVI ao XVIII, como prosa narrativa de ficção com personagens ou ações representando a vida diária, diferenciava-se do romance, forma mais longa e mais tradicional. No século XIX, com o declínio do romance antigo, de reminiscências medievais, a novel preencheu o espaço disponível, perdeu as associações originais, deixou de ser breve, virou romance. Hoje, novel, em inglês, é romance. E só no século XIX surge um termo específico para a estória curta, a short-story. Há ainda a long shortstory, para a novela, e o tale, para o conto e o conto popular (GOTLIB, 2001, p. 14).

É só a partir do ano de 1776, com a Independência do Estados Unidos levada a público, que o país vê a necessidade de desvencilhar-se dos modelos de literatura clássica da Inglaterra e de buscar uma literatura mais nacionalista. Ainda que essa necessidade se fizesse latente, a independência literária dos Estados Unidos tardou a acontecer, devido à persistência de identificação com os modelos ingleses e a crise econômica e política enfrentada pelo país na época, prejudicando a publicação de novos livros. 
Mais tarde, chega ao país o movimento romântico, definindo novos parâmetros para a literatura norte-americana. Movimento este que prezava a estética e o indivíduo, considerando o volume da obra e menosprezando obras de poucas páginas e que não tratassem somente do belo.

No que antes víamos uma exploração do estilo e estética góticas, com enfoque apenas no sobrenatural e no desconhecido, vemos, a partir de Poe, uma exploração da mente e dos vícios humanos, partindo das concepções bizarras, representando a literatura de terror de uma forma mais intensa, visando proporcionar ao leitor uma imersão na estória e ao mesmo tempo proporcionar deleite através da leitura.

Os contos acabaram se popularizando, devido a um grande público consumidor desse gênero que surgiu, justamente por causar o efeito que Poe afirmava eles possuírem: são estórias rápidas e que não são cansativas, prendendo assim a atenção de quem lê.

Com o conto tornando-se uma grande forma de expressão americana, selando a sua independência da literatura inglesa, muitas revistas começaram a publicar contos. E é de revistas e da venda de contos que surge a modernização do que foi preconizado a partir de Poe: o autor atual no gênero horror, Stephen King.

\title{
2.2 A simbologia do gato
}

\author{
"Gato preto, gato preto se foi \\ Se foi pra sempre, se foi por um bom tempo \\ Não acredito que ele me deixou sozinho \\ E espero que ele não volte para casa \\ Olhando para trás, o negro (passado) \\ Confiei nele uma vez, perdi minha direção \\ Confiei mais uma vez para salvar meus ossos \\ E nunca consegui voltar"
}

(Black Cat-Temple of the Dog)

Para entendermos melhor o foco deste trabalho, necessitamos compreender $\mathrm{o}$ simbolismo do gato e sua origem. Dentre tantos animais, ele surge, geralmente, conotando algo de misterioso, sobrenatural. Não é à toa que ambos os títulos estudados, "O Gato Preto" e "O Gato dos Infernos", revele de antemão ao leitor o protagonismo do felino em ambos os contos.

De acordo com Hyams (1972), além de ser intimamente associado ao diabólico, foi seu status de animal novo e recém-chegado na Europa - devido uma praga de ratos oriunda de levas 103

RELEDUC | ISE | v. 2 | n. 2 | ago. 2019 
migratórias germânicas -, o que teria lhe valido uma reputação ambígua. Além disso, certas características atribuídas ao gato, como hábitos noturnos, sua associação com a lua e seus "olhos enigmáticos" teriam também contribuído para esse mito.

Além disso, gatos eram fortemente associados ao paganismo e a religiões antigas. Conta-se que a deusa egípcia Bastet, de seu cesto divino, deixara escapar um de seus filhotes, uma esfinge que devorava quem não conseguisse decifrá-la, ficando à espreita, na encruzilhada do caminho que levava a Tebas. Édipo foi o único que conseguiu solucionar a charada fatal, ou melhor, foi o único que pensou tê-la resolvido. O mito da esfinge se metamorfoseia até chegar em Lilith e Eva, da Bíblia Cristã, que são, por essência, a mulher subversiva, que não se rende ao patriarcalismo. Na fé mesopotâmica, esse tipo de mulher era dada como demoníaca ou como um espírito ruim. Segundo as crenças, esses seres se manifestavam à noite, portanto, a mulher fatal modifica seu status ao longo da história transformando-se nas hereges bruxas que, segundo a concepção difundida e o reforço da ideia pelo cristianismo, eram esposas de Lúcifer e o cultuavam, levando milhares de mulheres e homens às suas derradeiras perdições.

Daremos para o presente trabalho relevo às feiticeiras, pois acredita-se também que elas transformavam-se em gatos, proles de Bastet.

Também, segundo Darnton (1986), as razões simbólicas do uso ritualístico do gato residiriam numa relação entre os felinos e a feitiçaria. Uma série de maneiras de torturar gatos consistia, na verdade, em livrar-se da feitiçaria ou das feiticeiras. Em relação a isso, os bichanos também impediam tarefas cotidianas de transcorrerem bem, como o crescimento do pão ou a pescaria. Seu uso ritualístico e mágico para atividades consideradas moralmente boas ou ruins indicava a ambiguidade do animal. Simbolicamente, era a sua correlação com o sobrenatural que o tornava propício a práticas mágicas.

Cores também são um item importante na simbologia do gato. Embora alguns filósofos não entendam o preto e o branco propriamente como cores, para uns representando o preto a privação de todas as cores e o branco representando a origem de todas elas, gatos pretos permanecem até os dias atuais estereotipados como aqueles que trazem má sorte, a personificação do obscuro e o branco, algo puro, imaculado, a personificação da luz. Em determinadas épocas do ano, em culturas específicas, as pessoas organizam uma espécie de caça aos gatos pretos, para realizarem rituais ou sacrifícios, devido à sua reputação.

\subsection{Análise dos contos}


"Todas suas questões podem ser respondidas, se isso é o que você quer. Mas uma vez que você aprende as respostas, você nunca mais pode desaprendê-las."

(Deuses Americanos - Neil Gaiman)

\subsubsection{Histórias}

O gato tem relevância primordial para que os contos gerem significado. A fim de analisar o enredo, faremos inicialmente um breve resumo de cada conto, a começar por $\mathrm{O}$ gato preto. Poe utiliza um narrador em primeira pessoa que, logo de início, nos faz perceber que a narrativa compõe-se através do relato memorial de um narrador- personagem às vésperas de sua condenação. A partir desse começo, o leitor é levado a compreender melhor uma mente que parece perturbada com os acontecimentos de um passado não tão distante. Somos alertados pelo próprio narrador de que esse relato pode ser falso, devido a sua confusão para distinguir o que é ou não real, deixando-nos a lacuna que propicia a dúvida: até que ponto os fatos apresentados no conto são reais e não frutos da mente atormentada do narrador?

Como os demais contos de Poe, o enredo apresenta muitas simbologias para a construção de sentido e apenas o personagem que carrega significado apresenta um nome. Neste, não sendo diferente, apenas o gato é identificado pelo nome de Pluto (ou Plutão), levando-nos a encavar um leque de representações que levam à uma única imagem: a da bruxa.

As informações que recebemos é que o locutor era afável e gostava de animais, casouse cedo com uma mulher bondosa e que compartilhava do mesmo sentimento. Tal docilidade por parte do narrador-personagem transmuta-se, pouco a pouco, em violência e ódio. Ainda que possuindo vários animais, o que mais amava era o gato Pluto, transformando-o em um alvo de seus ataques de fúria devido ao álcool. Um dia, em um desses acessos, enforca o animal em uma árvore à frente da casa. À noite, como um castigo sobrenatural, sua casa pega fogo, sobrando uma parede intacta, onde uma mancha transforma-se na forma de um felino estrangulado. Perturbado pela imagem, sente-se no dever de encontrar outro gato para suprir a perda do anterior. Nisso, encontra um gato desconhecido, quase idêntico ao primeiro, excluindo uma mancha no peito que, mais tardar, parece ao narrador-personagem a imagem de uma forca.

Logicamente, sua tentativa de recuperar quem era antes do "demônio da intemperança" é frustrada, uma vez que, cheio de cólera, tenta matar o segundo animal com um machado. Sua 
esposa, pondo-se entre o conflito, acaba por morrer no lugar do gato. Tomado pelo medo, empareda o corpo da falecida e sente-se aliviado. Confiante com o feito, quando é realizada uma espécie de batida policial em sua casa, bate na parede, de onde sai um guincho de gelar a alma, só para revelar mais tarde um animal vivo e delator, que fora emparedado junto com a mulher.

Em O gato dos infernos, King faz uso do narrador onisciente para contar uma história focada essencialmente nos personagens Drogan, dono de uma rede de indústrias farmacêuticas que testam seus medicamentos em gatos, devido seus sistemas nervosos; Halston, um matador profissional e, claro, o gato Sam, o qual Drogan acredita ter aniquilado todos seus colegas e que agora quer matá-lo.

O autor não se preocupa com simbologias, mas em apresentar acontecimentos que se enraízam na mente do leitor, para que este tome os fatos como reais.

Drogan, que afirma odiar felinos desde o início, acredita piamente que Sam deseja vingar-se pelos milhares de mortes de gatos promovidas pela empresa dele. Halston, assassino contratado, permanece incrédulo a maior parte do tempo, uma vez que o gato Sam mostra-se amigável e carinhoso com ele de início, não parecendo representar nada mais que uma imagem deturpada de uma mente idosa e solitária. As mortes dos colegas também apresentam caracteres comuns, mas deixam um sentimento de receio no leitor. Amanda, irmã de Drogan, é encontrada um dia ao pé da escada, morta. Carolyn, companheira de Amanda, morre dormindo. Dick Gage, empregado de Drogan, sofre um acidente de carro quando é instruído pelo mesmo a levar o animal para ser sacrificado. Todas as mortes são dadas como acidentais.

Mesmo duvidando, Halston aceita a oferta, que envolve um pagamento alto, para a realização do serviço. Pensando ser simples, dirige tranquilamente com o gato, até que é atacado pelo bichano, que o faz bater o carro. Tendo sofrido um choque medular e estar parcialmente imobilizado, o gato avança para seu rosto, entrando pela boca do matador. De manhã, o carro é encontrado por um fazendeiro local que presencia o gato cavando um buraco no estômago de Halston e saindo de dentro do mesmo. Ficamos com a ideia final que é incompleta na escrita, mas que está completa em nossa mente: o fazendeiro diz à reportagem que o gato foi embora e parecia apressado, sugerindo-nos que o bichano fora completar sua missão.

\subsubsection{Repertório}


Ambos os contos promovem informações breves sobre seus personagens e locais, focando-se prioritariamente nos acontecimentos. O cenário em $\mathrm{O}$ gato preto resume-se essencialmente em:

Ambientes externos: são locais que levam ao destino do narrador. A taverna e demais locais não mencionados que o transformam de um homem doce a um homem inquieto e irritadiço; o jardim da casa, onde enforca o gato e onde mais tarde, o narrador-protagonista, sua esposa e uma multidão assiste o incêndio da casa, como num adeus definitivo de tudo de bom que a casa ainda representava e de onde ele avista uma única parede intacta, com a figura "como em alto relevo" do gato.

Ambientes internos: são locais que definem o destino do narrador. A prisão, representando o aprisionamento físico, nos passando a informação, logo de início, de onde está escrevendo, detalhando os acontecimentos, a seu modo, que o levaram até ali; a casa, representando no começo um local harmonioso e seguro, que aos poucos passa a se tornar um local de conflitos e prisão figurada para os animais, a esposa do narrador e, de certa forma, até para o próprio narrador.

Os ambientes em $\mathrm{O}$ gato dos infernos resumem-se em:

Ambientes externos: são locais que definem os destinos de Drogan, quando seu empregado Dick Gage encontra o gato Sam e ao final do conto quando o fazendeiro diz ter visto o gato ir embora apressado; de Dick Gage, quando ele sai da mansão para levar o animal para ser sacrificado e de Halston, que também sai da mansão com o gato para levá-lo à morte.

Ambientes internos: são locais de conflito que levam ao fim dos personagens. A mansão de Drogan, onde morrem sua irmã e a colega da irmã, com mortes ditas acidentais e onde inferimos que Drogan também vá morrer no final do conto; o carro, tanto de Dick Gage quanto de Halston, onde ambos lutam contra o gato para sobreviverem e onde são encontrados mortos.

Os atores principais do conto de Edgar Allan Poe são o narrador-protagonista, sua esposa e o gato Pluto. Os atores principais do conto de Stephen King são Halston, Drogan e o gato Sam. Os demais personagens servem para dar significado a estória, mas não agem ativamente como os mencionados - ou nem agem diretamente.

\subsubsection{Análise e comparação}


Abaixo apresentamos um quadro comparativo com os pontos mais relevantes de cada conto, os quais discutiremos a seguir:

\begin{tabular}{|c|c|}
\hline O gato preto & O gato dos infernos \\
\hline Afeto a gatos até virar alcóolatra & Halston: afeto a gatos \\
Drogan: Desafeto a gatos desde o início
\end{tabular}

No primeiro item, observamos a relação dos protagonistas com os animais. O gato preto difere de $\mathrm{O}$ gato dos infernos, pois o narrador-protagonista no primeiro conto sente afeto pelo felino desde o início, até desenvolver o hábito de beber e acaba despertando em si uma fúria estupenda pelo animal Pluto. Ao início do conflito apresentado no enredo, o personagem maltrata todos os animais, exceto seu gato, conservando ainda consideração para com ele. No entanto, quando está entregue ao vício, acaba maltratando o bichano de forma mais cruel do que fizera com os demais animais, inclusive matando-o de forma brutal. Essa dualidade é evidenciada em:

Tinha particular afeição por animais e fui mimado por meus pais com uma grande variedade de bichos de estimação. Com eles passava a maior parte do tempo e nunca me sentia tão feliz como nas ocasiões em que os alimentava e acariciava. [...] Tornei-me, a cada dia, mais taciturno, mais irritável, mais sem consideração com os sentimentos alheios. [...] Meus bichos, é claro também sofreram com minha mudança de disposição. Eu não só os negligenciava, como também os maltratava (POE, 2012, p. 81 e 82). 
Quase da mesma forma que o protagonista da obra de Edgar Allan Poe mostra- se inicialmente, em $\mathrm{O}$ gato dos infernos, o assassino profissional sente afeição por gatos desde o início do conto:

Halston gostava de gatos. Eram os únicos animais de que gostava, para dizer a verdade. Eles se viravam sozinhos. Deus - se é que Ele existe

- havia feito deles máquinas de matar perfeitas, indiferentes. Gatos eram os matadores do mundo animal, e Halston os respeitava por isso (KING, 2011, p. 264).

Em contrapartida, vários trechos evidenciam o repúdio que outro personagem, Drogan, mostra em relação aos gatos, como evidencia sua fala: “[...] Eu nunca gostei de gatos. São uns animais nojentos, infestados de doenças...” (KING, 2011, p. 265) e na sequência quando o narrador afirma sobre Drogan: "Ele odiava gatos. Sempre odiara. Quando aquele se recusou a ser enxotado, ele ordenou que Gage lhe desse comida envenenada" (KING, 2011, p. 266).

A seguir, observamos os gatos em si e como eles são introduzidos na trama. Em O gato preto, há, primeiramente, Pluto, porém seu dono o mata enforcado. Um segundo gato é adotado não muito tempo depois, um felino misterioso que aparece na taverna que o narrador frequentava, sendo esse novo animal idêntico ao antigo,com exceção de uma mancha em volta de seu pescoço que, no começo, para o protagonista, era indistinta, mas por fim toma a forma de uma forca. O bichano, portanto, passa nesse instante a configurar uma memória delatora para o narrador- personagem, lembrando-o sempre que a maldade encontra-se em seu âmago e é indissociável dele. Em O gato dos infernos, o personagem Drogan introduz o animal a Halston, o assassino de aluguel. O gato Sam se aproxima de Halston, pulando em seu colo e ronrona enquanto ele o acaricia. Ao mesmo tempo, Drogan relata como o bichano assassinou duas mulheres que eram importantes para ele e um empregado da casa. Sam possui uma metade do corpo branca e outra preta, como que para enfatizar desde o princípio o que posteriormente vemos como a dualidade entre bem e mau presente nele.

Há, em ambos os contos inclusive, um sentimento de similaridade quando os gatos são vistos pela primeira vez. O narrador-protagonista de Poe vê no segundo gato uma nova versão de seu primeiro animal, como uma redenção pelos seus atos. Em King "o pensamento ecoou de volta para Halston: Nós nos conhecemos, eu e você”. (KING, 2011, p. 263). No caso do conto de Edgar Allan Poe, entendemos, baseado no desenrolar do enredo, que aquele novo gato desperta semelhança por algum motivo macabro e que algo está para acontecer. Em Stephen 
King, embora saibamos que algo ruim acontecerá em breve, ele não deixa explícito para o leitor o porquê do sentimento de semelhança para com o bichano. Podemos deduzir que Halston sente uma ligação com o gato, pois ambos são assassinos astutos.

A próxima relação é a respeito das drogas, presentes em ambos os contos. No entanto, enquanto em Poe o narrador é consumido pelo alcoolismo, despertando seu pior lado, em King, um dos personagens principais é dono de uma rede de laboratórios que desenvolveu uma droga receitada principalmente para pacientes com doenças terminais: Tri-dormalfenobarbina, complexo G, uma combinação de analgésico, tranquilizante e alucinógeno. Durante a fase de testes para o produto, o personagem Drogan matou, indiretamente, cerca de 15 mil gatos usados como cobaias para a droga.

No item seguinte, podemos assimilar dois fatos dos contos: a morte das personagens femininas. No conto $\mathrm{O}$ gato preto, o narrador assassina a própria esposa "por acidente". Devido ao contexto em que fora escrito, a América do século XIX, a figura feminina é frágil e, de certa forma, mediadora de conflitos, sempredemonstrando um ar angelical. Poe devota, em sua bibliografia, essa imagem da mulher e, não sendo diferente neste conto, a fragilidade da esposa do protagonista condizia com padrões impostos por uma sociedade. No conto de King, duas figuras femininas também falecem de forma considerada acidental. No entanto, há um porém: a fragilidade advém do peso da idade, pois ambas são mulheres idosas, sendo assim, contrárias neste caso à mulher em Poe.

Analisamos também a nomeação dos personagens, que dá personalidade e relevância para os mesmos na estória. Em O gato preto, apenas o gato é nomeado, pois seu nome carrega um significado que define toda a trama: Pluto - ou Plutão - é como ficou conhecido Hades, o deus do submundo, na mitologia romana. No entanto, mesmo que o nome do narrador não seja mencionado - característica típica dos contos de Poe - ele é de extrema relevância, porque é ele quem move toda a estória, a partir do momento em que desenvolve seu vício por álcool. Em O gato dos infernos, todos os personagens recebem nomes relativamente comuns - Drogan, Halston e Sam -, sem que carreguem algum significado profundo. Eles possuem significação pelo seu papel na estória, por suas ações.

A simbologia dos gatos é o item seguinte. O gato preto de Poe relaciona-se à bruxaria, conceito muito sólido no século XVIII, pois acreditava-se que os gatos - principalmente os de cor preta - eram bruxas disfarçadas. O conceito foi se modificando ao longo dos séculos e, ao 
chegar em King e ao contexto do século XX, o gato representa astúcia e mistério, pela sua autossuficiência e inteligência, se comparada a de outros animais.

O ponto seguinte é a cor das manchas nos gatos. Em ambos os textos, duas cores são utilizadas: preto e branco, representando, assim, o bem e o mal, ou a pureza e a malícia, que se encontram nos animais dos contos. O preto também aparece como sinônimo de escuridão, enquanto o branco aparece como sinônimo de clareza. O primeiro gato no conto de Poe é completamente preto, já o segundo é preto como uma mancha branca que envolve seu pescoço, na forma de uma forca (do ponto de vista do narrador). No conto de King, o corpo do animal é dividido em preto e branco, representando a pureza e inocência que o animal demonstra no início do conto e, conforme o enredo vai se desenrolando, a maldade do gato vêm à tona e tornase ainda mais explícita ao nos aproximarmos do clímax do texto. É possível citar, inclusive, que a maior parte dos conflitos ocorrem à noite. Em O gato preto, é na parteda noite que o narrador sai para beber, é nesse período também que ocorre o incêndio da casa, por exemplo. Em O gato dos infernos, é à noite que ocorrem a maioria das mortes na trama. Ou seja, trevas. No entanto, é de dia que ocorrem os momentos de clareza, estabilidade nas estórias, como um solvente dos problemas que acontecem ao anoitecer.

A seguir, observamos que há uma diferença entre os contos no quesito protagonista. Em O gato preto, o narrador-protagonista é um indivíduo comum, que, após embriagado, tem sua índole maculada e, a partir disso, assassina a própria esposa e seus animais. Em O gato dos infernos, Halston é um assassino de aluguel, ou seja: matar é seu trabalho, e sua tarefa seguinte é assassinar o gato da mansão de Drogan. Há um quê no conto: é o gato que apresenta-se como o verdadeiro assassino, pois elimina cada personagem de maneira peculiar, com a astúcia que só um felino possui.

Em ambos os contos, apenas o animal sobrevive ao final, a contar que, no conto de Poe, o narrador morrerá enforcado pelo homicídio da esposa e ocultamento de cadáver delatado pelo gato, como ele mesmo relata de início, enquanto no conto de King, o próprio gato se encarrega de assassinar todos os personagens relevantes da estória. Mesmo que a execução por enforcamento fosse considerada algo comum para assassinos na época em que o conto foi escrito, interligamos, ainda, o fato do protagonista de $\mathrm{O}$ gato preto ter enforcado o felino e também dele ter sido enforcado como mais uma alusão à uma das execuções impostas às pessoas consideradas bruxas na Idade Média, sugerindo que ambos entregaram-se definitivamente ao paganismo, a considerar a persistência da referência às bruxas e suas práticas 
bastante presentes nesse conto. Já em O gato dos infernos, é como se o gato Sam fosse o próprio ceifador, tirando vidas. Sendo assim, as duas estórias apresentam animais que sugerem, de formas diferentes, que estão levando os demais personagens para o inferno e que são eles que irão ser juízes dos atos de cada um.

O item seguinte se dá por outra semelhança encontrada entre os contos, sendo que, no conto de Poe, o segundo gato é encontrado em uma cavidade na parede da casa do narrador, aberta pelo mesmo, junto do cadáver da esposa assassinada. No conto de King, o gato também é encontrado em uma cavidade, porém feita pelo próprio animal: um buraco no estômago do assassino de aluguel Halston, emergindo deste e seguindo para seu próximo alvo: o velho Drogan.

Por último e não menos importante, é possível sustentar que ambos os contos criam um ambiente de opressão através dos acontecimentos narrados. No entanto, também podemos dizer que Poe cria toda a sua narrativa baseada principalmente nas superstições que assombravam a sociedade do século XIX, ao invés de construir o elemento de horror a partir de um momento de conflito. Ele parte, portanto, da crença que o animal já tem em si o poder do profano e é sua natureza de bruxa que leva o narrador-protagonista a abraçar o paganismo e condenar sua alma. King, por sua vez, faz uso da realidade como geradora do elemento sobrenatural, uma vez que a morte em massa de gatos de teste fez com que um animal crie uma consciência, como que possuído pelo senso de vingança, a ponto de distorcer essa realidade e tornar-se um justiceiro. Uma evidência disso é o próprio gato, que carrega em si o maligno e logo, é "dos infernos". Portanto, mais simples que Poe, King expõe através da narração e diálogos claros diversas situações e como os personagens reagem a cada uma delas.

\section{CONSIDERAÇÕES FINAIS}

Buscamos investigar as semelhanças e diferenças apresentadas na problemática do trabalho, inferindo, inclusive, que a simbologia do gato metamorfoseou-se entre os períodos dos contos, de modo que as obras sejam paralelas, mas não idênticas.

Pudemos compreender que $\mathrm{O}$ gato preto trata-se das confusões mentais e da loucura de um personagem que cria, a partir da crença popular do gato como ser místico - e também, mítico -, uma atmosfera de opressão, de abafamento que leva o leitor a pensar no gato como o próprio agente do diabo, o instigador do conflito e dos maus comportamentos que aliciam o 
narrador a depreciar-se até o seu derradeiro fim. Já no caso de O gato dos infernos, concluímos que o conto se ampara na noção de que o gato é um ser astucioso por natureza e, sendo assim, ele detém o poder de ser aquilo que quiser, inclusive de criar a consciência que pode transformálo de um mero felino em um animal possuidor do senso de julgamento, desenvolvendo, a partir disso, sua característica sobrenatural. Temos, portanto, dois cenários: o do cotidiano sustentado pelo místico e o do cotidiano que ganha "misticidade" a partir do conflito principal.

Para, além disso, pudemos admitir que ambos os autores usam de suas realidades para comporem os contos, tratando não só de crenças relacionadas a uma era, mas também de vícios de uma era, como o ópio e o álcool em Poe e os antidepressivos e analgésicos em King. Não obstante, também acreditamos que haja uma inspiração em Edgar Allan Poe por parte de Stephen King, ainda que inconscientemente, pois o autor diz ser um leitor ávido de Poe. No entanto, ele afirma ainda que o conto:

[...] veio a ser escrito de uma maneira curiosa. O editor responsável pelas ficções da Cavalier [revista masculina americana a qual o autor escrevia contos] na época [...] me mandou uma fotografia em close de um gato rosnando. O que a tornava incomum - além da ira do gato - era a maneira como seu rosto era dividido pela metade, o pelo branco de um lado e, do outro, de um preto lustroso. Nye [o editor] queria fazer um concurso de contos. Ele propôs que eu escrevesse as primeiras quinhentas palavras de uma história sobre o gato; eles então pediram aos leitores para termina-la [...]. Eu concordei, mas fiquei interessado o suficiente pelo conto para escrevê-lo até o fim (KING, 2011, p. 395-396).

Neste trabalho, inclusive, apresentamos especulações sobre o gato através da história e de crenças difundidas através dos séculos, em uma tentativa de evidenciar seu significado e função em cada um dos contos.

Também tivemos a percepção de que o contexto da época faz com que as obras difiram em estilo de escrita. Vê-se em Poe o reflexo da necessidade de se manter ainda certo preciosismo em sua composição, carregando o enredo de significado, adjetivos e advérbios que pesam na construção do cenário no imaginário do leitor. Em King, como não há mais a necessidade de seguir um padrão romântico inglês, o autor constrói parágrafos menos estruturados e carregados. Parafraseando o mesmo, podemos dizer que seu conto se trata da "batida, não da melodia" (KING, 2015, p.116), isto é, Stephen King foca-se mais na ação do que na construção do cenário, apresentando assim um enredo aparentemente simples, mas que envolve o leitor. 
Quanto às similaridades observadas, os contos apoiam-se em uma imagem popular do gato, amplamente difundida, deixando claro o protagonismo do mesmo. Sendo assim, podemos dizer que o gato de Poe reencarna no gato de King, pois preservam em si a astúcia e o pagão e, ao fazermos à leitura de ambas as obras, os felinos parecem possuir extrema semelhança, podendo afirmar até que ambos são o mesmo, mas adaptados à época, reforçando a ideia da mítica prole de Bastet que se modifica. Podemos dizer ainda que ambos possuem em comum o ritmo, mantido seja pelo sobrenatural ou pelo suspense, devido ao gênero escolhido que, como afirmado anteriormente, promove o aproveitamento da obra em sua totalidade.

Portanto, essa pesquisa buscou evidenciar que o gênero gótico não morreu, mas apenas se adaptou a uma nova época, transformando o estilo e o gênero. Também as crenças no sobrenatural foram incorporadas e metamorfoseadas de acordo com o avanço da globalização e a mudança das eras, preservando até os dias atuais um resquício das crenças consolidadas na Idade Média.

\section{REFERÊNCIAS}

DARNTON, R. Os trabalhadores se revoltam: o grande massacre de gatos na Rua SaintSéverin. In: O grande massacre de gatos e outros episódios da história cultural francesa. Rio de Janeiro: Graal, p. 103-139, 1986.

GOTLIB, N, B. Teoria do conto. 11 ed. São Paulo: Ática, p. 95, 2006.

HYAMS, E. Animals in the Service of Man: 10.000 Years of Domestication. Londres: J. M. Dent\& Sons Ltda., 1972.

KING, S. Ao cair da noite. Tradução de Fabiano Morais. Rio de Janeiro: Objetiva, 398 p, 2011.

POE, E. A. Contos de imaginação e mistério. Tradução de Cássio de Arantes Leite. $1^{\text {a }}$ ed. São Paulo: Tordesilhas, 423 p, 2012.

TODOROV, T. Introdução à literatura fantástica. São Paulo: Perspectiva, 2008.

VASCONCELOS, S. G. Romance gótico: persistência do romanesco. In: Dez lições sobre o romance inglês do século XVIII. São Paulo: Boitempo, 2002.

WALTHERS, G.D. Understanding the popular appeal of horror cinema: an integratedinteractive model. Journal of Media Psychology, Volume 9, 13 de ago. $2004 \mathrm{~N}^{\circ} 2$. Disponível em: $<$ http://web.calstatela.edu/faculty/sfischo/horrormoviesRev2.htm>. Acesso em: 26 de nov. 2016. 